Revista Interdisciplinaria de Estudioș de Género de El Colegio de México. 6. dossier Genero y Trabajo, e501

http://dx.doi.org/10.24201/reg.v6i0.501

Artículo

Dossier Género y Trabajo

\title{
Transiciones en los trabajos de hombres y mujeres ante la desestructuración del sector energético en México ${ }^{1}$
}

\section{Shifts in the Occupations of Men and Women Following the Restructuring of Mexico's Energy Sector}

\author{
Georgina Rojas García* \\ Eleocadio Martínez Silva² \\ Edgar Belmont Cortés 3
}

${ }^{1 *}$ Centro de Investigaciones y Estudios Superiores en Antropología Social (CIESAS), Ciudad de México, México. email: georgina@ciesas.edu.mx.

Ohttps://orcid.org/0000-0003-2334-5215. *Autora para correspondencia.

2Universidad Autónoma de Nuevo León (UANL), Monterrey. México.

email: eleocadio.martinezslv@uanl.edu.mx. Dhttps://orcid.org/0000-0002-8495-9475

${ }^{3}$ Universidad Autónoma de Querétaro (UAQ), Querétaro, México.

email: edgar.belmont@uaq.edu.mx Ohttps://orcid.org/0000-0002-7507-4552

Recibido 30 de agosto de

2019

Aceptado: 01 de junio de

2020

Publicado: 29 de junio de 2020

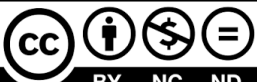

Esta obra está protegida bajo una Licencia Creative Commons AtribuciónNoComercial-SinDerivadas

\section{Resumen:}

En este artículo buscamos examinar cómo la desestructuración productiva del sector energético ha repercutido sobre los arreglos entre hombres y mujeres alrededor de la gestión de los espacios laboral y doméstico. Seleccionamos

CÓMO CITAR: Rojas, Georgina; Martínez, Eleocadio y Belmont, Edgar. (2020). Transiciones en los trabajos de hombres y mujeres ante la desestructuración del sector energético en México. Revista Interdisciplinaria de Estudios de Género de El Colegio de México, 6, e501, dossier Género y Trabajo. doi: http://dx.doi.org/10.24201/reg.v6i0.501

\footnotetext{
${ }^{1}$ Texto derivado del proyecto "La desestructuración de enclaves productivos energéticos: ajustes estructurales, respuestas locales, gestión del territorio y tejido social”, financiado por Conacyt, con el registro 221545.
} 
dos ciudades como casos de estudio (Necaxa, Puebla y Ciudad Pemex, Tabasco) y utilizamos información cuantitativa y cualitativa obtenida de primera mano. El empleo estable del sector energético permitió sostener por décadas la tradicional división sexual del trabajo entre hombres y mujeres en el hogar y fuera de él. Ante el intento de seguir reproduciendo los roles tradicionales de género, los hombres ven cuestionado su papel de proveedores principales y las mujeres salen a un mercado que fue predominantemente masculino. Ellas encuentran la doble jornada, pero ganan presencia en la calle.

Palabras clave: sector energético; ajuste estructural; cierres de empresas; división sexual del trabajo; segregación en el trabajo; papeles de género.

\begin{abstract}
:
This article examines how the restructuring of energy production in Mexico has affected the arrangements between men and women in terms of managing the workplace and the domestic sphere. Two cities were as case studies (Necaxa, in the state of Puebla, and Ciudad Pemex, in the state of Tabasco), and a methodology of first-hand, quantitative and qualitative was applied. For decades, stable employment in the energy sector sustained the traditional gender-based division of labor between men and women in outside the home. Faced with the attempt to continue reproducing traditional gender roles, men are questioning their role as main suppliers and women are entering a job market used to be predominantly male. Women find themselves working double shifts but are now gaining a foothold in the job market.
\end{abstract}

Keywords: energy sector; structural adjustment; business closure; genderbased division of labor; labor segregation; gender roles. 


\section{Introducción}

Este texto es producto de una investigación más amplia sobre la desestructuración del sector energético en México. Aquí nos proponemos examinar las repercusiones de los ajustes estructurales en las relaciones que establecen hombres y mujeres, en dos antiguos enclaves energéticos y comprender los acomodos en el mercado laboral, de espacios que históricamente se han construido alrededor del sector energético que, cabe destacar, ha sido un terreno masculinizado. Nuestra atención estará puesta en la abrupta ruptura de las lógicas de reproducción social que se construyeron en los casos de estudio, así como en la división sexual de las relaciones de trabajo y salariales. En el proceso de desestructuración de las relaciones sociales, que se instituyeron alrededor del enclave, se observa una tendencia que aproxima las condiciones laborales de hombres y de mujeres, en principio porque la figura del proveedor está siendo trastocada y porque la inserción de las mujeres al mercado de trabajo es más que una estrategia para generar un complemento al gasto en el hogar.

El reto de este estudio ha sido documentar un fenómeno social en curso y que altera el entramado de relaciones sociales que se crearon alrededor de la centralidad que se le asignó al empleo en los dos enclaves energéticos. En la transición hacia una organización económica con otro carácter, se modifican prácticamente todos los ámbitos de la vida (Estrada, 1996). Sin embargo, todavía se ha explorado escasamente cómo en ese trance se transforman las relaciones entre hombres y mujeres y, en particular, cómo se ajusta el papel de las mujeres.

La reestructuración productiva en México, iniciada en la década de 1980, implicó, entre otras acciones, el cierre o la privatización de empresas paraestatales y, con ello, la crisis de ciudades o regiones cuya organización económica y social había sido altamente dependiente de una sola empresa (Estrada, 1996; Contreras, 2002; Rojas, 2007; Martínez, 2009). Sostenemos que el caso que nos ocupa, el sector energético, puede entenderse mejor con una mirada de mediano plazo, pues corresponde a la misma lógica de reestructuración del aparato productivo que inició en los ochenta. Salvo el caso documentado por Estrada (1996), en la etapa temprana de la reestructuración, el sector energético no había sido trastocado de manera tan directa y contundente como en años recientes (Belmont, 2016). 
Buscamos entonces, examinar cómo la desestructuración productiva del sector energético repercute sobre los arreglos entre hombres y mujeres, alrededor de la gestión de los espacios laboral y doméstico. No solamente los roles asignados a los sexos se modifican, sino que también la incertidumbre ante la pérdida de la protección social y la doble jornada de las mujeres, parafraseando a Hirata y Kergoat (1993), han puesto en cuestionamiento la unidad de la clase obrera, la cual, de repente, "tiene dos sexos" con trayectorias laborales cada vez más porosas e inestables. Dos son las preguntas que han guiado nuestra investigación: ¿Cómo se ha modificado la participación de hombres y mujeres en las esferas laboral y doméstica a partir de la desestructuración del sector energético? ¿Qué obtienen y qué dejan de obtener en términos de poder, prestigio y autoestima?

Para llevar a cabo la investigación seleccionamos dos ciudades como casos de estudio. Ambas fueron fundadas como enclaves energéticos e impulsadas por el Estado mexicano como parte de su proyecto de industrialización del país. Se trata de Necaxa, en el municipio de Juan Galindo, Puebla y de Ciudad Pemex, en Macuspana, Tabasco. Necaxa, "la cuna de la industria eléctrica", es un complejo hidroeléctrico construido a inicios del siglo XX, y la sede de la empresa pública Luz y Fuerza del Centro (LyFC), cerrada en 2009; actualmente cuenta con más de diez mil habitantes. Ciudad Pemex tiene aproximadamente cinco mil habitantes, la fundó el gobierno federal en 1958 para albergar a los trabajadores de un complejo de pozos que laboran en la extracción de gas y de hidrocarburos. Ambos espacios resienten las consecuencias de los ajustes estructurales y, en el caso de Ciudad Pemex, del agotamiento de los yacimientos petrolíferos. Ambas ciudades siguen albergando a población trabajadora cuyo sustento ha dependido, sobre todo, del bienestar de la industria energética.

La metodología utilizada en el estudio contempla tanto datos cualitativos como cuantitativos. La información cuantitativa proviene, sobre todo, de una encuesta realizada en las ciudades de Necaxa, Puebla y Ciudad Pemex, Tabasco. La encuesta fue diseñada para captar información sobre la desestructuración de la industria energética en las dos ciudades. El universo fue la población de 18 años o más; las manzanas se eligieron mediante un muestreo aleatorio simple, tomando como referencia el marco muestral del Instituto Nacional de 
Estadística y Geografía (INEGI) ${ }^{2}$. Se levantaron 400 cuestionarios en total, 200 en cada localidad. El levantamiento se llevó a cabo cara a cara en las viviendas de las zonas seleccionadas durante el verano de 2016.

La información cualitativa es producto de diferentes estancias en campo en ambas ciudades entre 2015 y 2017, en las que el equipo de investigación —conformado por académicos y estudiantes de licenciatura antropología y de posgrado — hizo contacto con diversos actores involucrados en la problemática, entre los que destacan los trabajadores y sus familias, así como líderes sindicales. Las técnicas utilizadas fueron principalmente observación y entrevistas en profundidad semiestructuradas (mediante autorización grabamos el audio). De acuerdo con problemáticas específicas de mayor interés, el equipo se dividió en los recorridos de campo durante las visitas. No obstante, para ampliar la perspectiva de todo el equipo, tratamos de compartir la información captada y tener discusiones colectivas sobre lo detectado cada día en campo. Se entrevistó a hombres y mujeres de las localidades independientemente de su vinculación con la empresa energética y se intentó una máxima variabilidad respecto de edad y escolaridad. Para el presente artículo se seleccionaron entrevistas a trabajadores de las empresas energéticas y esposas de obreros. A los dos casos de estudio se les da un trato metodológico homogéneo en función de que pertenecen a una misma cohorte generacional que compartieron las mismas experiencias de trabajo, sindicalismo, arreglos corporativos, de reestructuración, de despido y de reconfiguración de relaciones sociales incluidas las de género y familiares. Todo el estudio fue auspiciado por el Consejo Nacional de Ciencia y Tecnología (CONACYT).

En el primer apartado del artículo presentamos una propuesta de marco analítico para el abordaje de la reestructuración económica, trabajo y género. Posteriormente presentamos de manera breve los contextos de los dos enclaves energéticos estudiados. En el tercer apartado, a partir de nuestra información empírica examinamos qué tanto se cuestionan o modifican los roles tradicionales, socialmente asignados a hombres y mujeres, en las familias obreras del sector energético. Cerramos con comentarios finales.

\footnotetext{
2 Debido al tamaño de las localidades de interés, se realizaron reemplazos de las manzanas (bloques de viviendas) de la zona para conseguir la aplicación de 200 cuestionarios por ciudad.
} 


\section{Algunos elementos para el debate: reestructuración, trabajo y género}

El viraje en el modelo económico emprendido a partir de los años ochenta en diferentes partes del mundo, en México se llevó a cabo de manera rápida y drástica de tal modo que los propios organismos internacionales ponían al país como ejemplo de lo que se podía hacer para lograr la llamada estabilidad macroeconómica (Zepeda, Wise y Gallagher, 2009). Las medidas utilizadas consistieron en la liberalización comercial, la apertura al capital extranjero, el cierre o privatización de empresas paraestatales, la disminución del gasto público en inversión productiva y la reorientación del gasto social (Dussel, 1995; Roberts, 1991).

La reestructuración productiva, propiamente, se identificó con la reorganización de los procesos de producción, la participación relativa de los sectores económicos, la flexibilización del empleo y el cambio en las relaciones laborales (De la Garza, 2006). Las múltiples aristas que tuvo esta transformación macroeconómica son resumidas por De la $\mathrm{O}$ (2000) de la siguiente manera:

...las modificaciones sustanciales a los sistemas de contratación colectiva e individual, tipo de remuneración, temporalidad en el empleo, modificaciones en la jornada de trabajo, nuevas formas de organización de las tareas, a lado de una gradual disminución de la participación del Estado en materia de legislación laboral, seguridad social y del empleo, fueron definidas como estrategias de flexibilidad laboral (De la O, 2000, p. 98).

De acuerdo con Hirata (1998), inicialmente estos cambios fueron estudiados como si ante ellos no existieran diferencias entre hombres y mujeres, eran pues gender-blinded. No obstante, la creciente participación femenina en la fuerza de trabajo registrada justamente de los años ochenta en adelante ha sido ampliamente documentada, de manera que se ha mostrado que las mujeres llegaron en condiciones poco favorables:

...la segmentación por género no sólo se ubica de manera horizontal, limitando el empleo femenino a ciertos sectores y segmentos productivos...o 
en ciertos puestos. También se da en el interior de los procesos de trabajo, y se manifiesta en una limitada oferta de oportunidades para ascender profesionalmente, para asumir mayores responsabilidades... (De la Garza, Lara y Torres, 2001, p. 133).

Se ha enfatizado en diversos estudios que la situación subordinada de las mujeres en la esfera laboral no se debe a una "condición" imposible de superar (Lara, 1991). Sino que ésta se explica por las desigualdades de clase y género que se ponen en juego en el mercado de trabajo. Se han propuesto herramientas analíticas para desvelar tales desigualdades:

Lo concreto de la vida real no se presenta de manera dual sino como un conjunto integrado, en el que las relaciones múltiples de dominiosubordinación — basadas en raza, edad, caracteres étnicos, nacionalidad, preferencia sexual - interactúan de manera dialéctica con las relaciones de clase y género (Ravelo, 2001, p. 146 [cita a Benería y Roldán, 1992, p. 22]).

En estas relaciones de dominio-subordinación no predomina la clase sobre el género, pues ambas categorías son estructurantes, hay más bien "una reciprocidad de la interacción de género y clase” (Ravelo, 2001, p. 148). Sostiene la autora: "El género es una relación, la clase es otra, y juntos constituyen una relación diferente..." (Ravelo, 2001, p. 148). Esta relación diferente, proponemos en este estudio, puede ser observada en la familia obrera.

La industria básica desarrollada con el modelo de empresa integrada — como es el caso de las empresas del sector energético estudiadas - pervivió con base en arreglos corporativos con los trabajadores, mediados por los sindicatos respectivos. Estos acuerdos con los sindicatos se apoyaron en el reconocimiento de la calificación técnica y la protección del estatus del trabajador (electricista y petrolero). En este sentido, la regulación monopólica del mercado energético se tradujo en la protección del mercado de trabajo y en la construcción de lógicas de reproducción social mediadas por la idea de patrimonio y la defensa de un modelo de familia (petrolera y electricista). 
La robustez de esta "familia” se basó en dos pilares: por una parte, la transmisión de la plaza, reconocida en el contrato colectivo de trabajo como derecho del trabajador al jubilarse y, por otra parte, en "toda una política de concesiones, de elevados salarios y prestaciones" (Quintal, 1986, p. 113). Estos pactos corporativos permitieron tener - y vislumbrar para generaciones subsecuentes - un empleo formal, estable y con amplios beneficios sociales de por vida. Este empleo aseguraba la manutención familiar con un nivel de vida decoroso. Una característica de esta familia también fue una división sexual del trabajo tradicional (Pacheco y Blanco, 2011), correspondiente al "modelo breadwinner" (Seccombe, 1993). En esta familia el varón adulto es el principal o único proveedor, a partir de su trabajo que le proporciona un "salario familiar", es decir, suficiente para la manutención del núcleo. Asimismo, a la mujer le atañe ser madre-esposa y ama de casa, quien depende de los ingresos logrados por el esposo y se espera que reciproque con el cuidado y la buena administración de estos (De Barbieri, 1984). Esta organización doméstica y extradoméstica no sólo implica dependencia económica de la mujer, sino también que la autoridad se deposita en el esposo, el proveedor (De Barbieri, 1984; Seccombe, 1993).

En los dos estudios de caso en cuestión - Necaxa y Ciudad Pemex — el modelo breadwinner estuvo vigente no sólo porque los ingresos que obtenían los hombres adultos jefes de hogar tenían un poder adquisitivo mayor al que se conoce desde la década de 1980 (Bortz y Águila, 2006), sino también porque venía acompañado de conductas y de valores que socialmente eran los esperados. Sin embargo, la naturalización de los roles tradicionales mantendría latente las tensiones que se construían en el espacio doméstico pues el empleo estable y el salario regular - asignado al hombre - constituía al mismo tiempo una fuente de jerarquía y de desigualdad en las relaciones entre ambos sexos (Federici, 2018). Por ello, de acuerdo con Hirarta y Kergoat (1993), la unidad — solidaridad orgánica e integración social— de la clase obrera ha sido meramente un mito.

El proceso de reestructuración productiva que comenzó a configurarse en México, en la década de los 1980, significó un trastrocamiento del modelo de la familia proletaria, no sólo con la pérdida de seguridad en el empleo, sino también con la incorporación creciente de las mujeres, en condiciones de desigualdad, al mercado de trabajo. La segmentación del mercado 
de trabajo y la flexibilización de las relaciones laborales acentuaron, por lo tanto, las brechas entre hombres y mujeres en el marco de una desafiliación a los colectivos y de la desprotección social.

\section{Auge y desestructuración de los enclaves energéticos}

Los dos casos de estudio en esta investigación tienen algunas características similares, pero otras que los diferencian. Ambos se desarrollaron como parte del proyecto industrial (de impulso a la industria básica nacional) del Estado mexicano y estuvieron dedicados al sector energético considerado estratégico. Ambas ciudades fueron fundadas como enclave y, si bien para cuando los alcanzó la desestructuración su organización podía haberse mantenido o no, usamos la categoría por su utilidad metodológica para comprender la estrecha relación entre el centro productivo y los espacios extra productivos.

En el enclave, la vinculación entre un centro productor (una mina, un campamento petrolero, un puerto, una fundición) y los servicios urbanos necesarios para mantener a sus trabajadores y sus familias son muy estrechos (Zapata, 1977). Por ello, la reestructuración de los enclaves industriales ha cimbrado la organización social de aquellos lugares donde se ha llevado a cabo (Contreras, 2002; Estrada, 1996; Rojas, 2007). La materialización de dichos cambios ha trastocado el conjunto de relaciones sociales en las cuales hombres y mujeres de diferentes generaciones habían sido socializados.

A principios del siglo XX el presidente Porfirio Díaz (1884 - 1911) autorizó la creación del Complejo Hidroeléctrico de Necaxa ( $\mathrm{CHN}$ ), en el estado de Puebla, concesionado a la empresa Mexican Light and Power de capital canadiense. Dicho Complejo se construyó entre 1903 y 1911 e implicó una transformación tanto geográfica como sociocultural (Colín, 2018). En principio, se anegó la zona ocupada por diferentes comunidades de origen nahua (como Acuautlán, Pataltecoya y Necaxa) que, a pesar de oponer resistencia, fueron desalojadas. Parte de su población aceptó reubicarse en los poblados fundados alrededor del complejo hidroeléctrico - como Nuevo Necaxa o "Canaditas"- pero la mayoría se fue a las zonas altas aledañas, como Necaxatépetl. El espacio urbano que albergaría a los trabajadores 
electricistas fue diseñado por completo por la empresa eléctrica concesionaria. En 1936 se constituyó el municipio de Juan Galindo, que reunió a los pueblos de Nuevo Necaxa y Necaxa. Desde entonces el CHN mantuvo un fuerte vínculo tanto con la comunidad de Nuevo Necaxa como con la Ciudad de México y los centros mineros y textiles del vecino estado de Hidalgo.

Este enclave fue muy dinámico durante décadas justamente por su cercanía con la Ciudad de México y otras localidades electricistas del centro del país. Trabajadores oriundos de Nuevo Necaxa se desempeñaban allá mismo o en otras ciudades, como en la capital del país, de manera que había vínculos e información en torno al funcionamiento del enclave electricista. El entramado pudo consolidarse en buena medida por la fuerza adquirida por el Sindicato Mexicano de Electricistas (SME), fundado en 1914. En 1960 se nacionalizó la industria eléctrica y la empresa pasó a llamarse “Compañía Mexicana de Luz y Fuerza” o "Luz y Fuerza del Centro" (LyFC). La población del enclave, lo que hoy es el municipio Juan Galindo, Nueva Necaxa, ha sido pequeña; en la actualidad cuenta con alrededor de 10 mil habitantes.

En octubre de 2009, el gobierno mexicano decretó la extinción de la empresa LyFC, encargada de suministrar electricidad a la región centro del país, incluida la Ciudad de México ${ }^{3}$. El cierre representó la culminación de un largo proceso de desmantelamiento de la empresa. Durante décadas se le impusieron restricciones financieras, endeudamiento, escasez de inversión tecnológica y deterioro de la infraestructura, además de las limitaciones para generar energía eléctrica, lo que obligó a la empresa a comprar a Comisión Federal de Electricidad (CFE) el 95\% de la energía que distribuía (Belmont, 2013). La extinción de esta fuente de trabajo significó también el despido de 44 mil trabajadores y un golpe a una decena de comunidades de electricistas en la región centro del país. El gobierno federal ofreció una liquidación que dividió a los electricistas, de manera definitiva, pues la mayoría aceptó la oferta. No obstante, alrededor de 16 mil decidieron dar la batalla por retornar al trabajo en la empresa sustituta (CFE) y recuperar su fuente de trabajo.

\footnotetext{
${ }^{3}$ La otra empresa estatal, CFE, cubría la demanda del resto del país.
} 
En la ciudad de Necaxa, la resistencia, como se le llamó al movimiento de oposición al cierre, se dio de manera activa entre 2009 y 2016. Entre las actividades de protesta llevadas a cabo se observaron la toma de plazas, bloqueo de carreteras, puestos de vigilancia permanente en puntos de acceso a la planta hidroeléctrica, acciones legales ante instancias laborales y judiciales y la búsqueda de salidas políticas al conflicto. El papel del SME como aglutinador y para dar dirección al movimiento fue crucial (Belmont, 2013; Victoria, 2013).

En 2016 el SME llegó a un acuerdo político con el gobierno federal: se le otorgarían activos a los trabajadores, que podrían explotar durante 30 años, a cambio de que renunciaran al pasivo laboral de 80 mil millones de pesos de los trabajadores que no aceptaron su liquidación tras la extinción de LyFC. Con el acuerdo del sindicato, los trabajadores obtuvieron el derecho de operar 14 plantas hidroeléctricas y cuatro plantas de ciclo combinado ubicadas en el Estado de México, Distrito Federal (ahora Ciudad de México), Puebla, Hidalgo y Tlaxcala. Con este acuerdo se abrió la posibilidad de retornar al trabajo.

Cualquiera que sea el desenlace de este proceso, lo cierto es que los pobladores de Nueva Necaxa difícilmente volverán a experimentar un empleo estable, confiable, decente, ya que desafortunadamente sólo duró un breve momento en la historia. Cuando se cerró LyFC en 2009, alrededor de 800 trabajadores de la localidad - lo que representaba el $17.5 \%$ de la fuerza de trabajo - se quedaron sin empleo (Reyes, 2018). Cientos de ex electricistas disputan empleos de menor calidad, anteriormente reservados para las mujeres y para los hombres que no lograban insertarse en la compañía eléctrica.

Por otra parte, el enclave petrolero de Ciudad Pemex es mucho más joven. La nacionalización de la industria petrolera (1938) fue una pieza clave para la expansión de la infraestructura energética del país y el impulso del proyecto de industrialización por sustitución de importaciones. La transformación del territorio en el sureste mexicano, en particular el estado de Tabasco, se manifestó con la explotación de los recursos energéticos, la instalación de pozos petroleros y de centros de almacenamiento, provocando la transformación del paisaje social y la construcción de comunidades de trabajadores que se identificaron como petroleros. Para la década de 1950 los campos de explotación de hidrocarburos (Gutiérrez, 1950) 
configuraban ya una economía de enclave, y una fuerte identidad laboral articulada con la industria extractiva.

Los procesos de expropiación de terrenos para la creación de unidades productivas (pozos petroleros, unidades de almacenamiento y planta procesadora de gas) en el municipio de Macuspana, generaron conflictos agrarios y ambientales. Con el tiempo estos procesos legitimaron la sujeción del territorio a la lógica de desarrollo impuesta por el Estado, la creación del mercado de trabajo petrolero, acorde con la dinámica de la industria, creó una comunidad de trabajadores que legitimaría, en nombre del interés nacional, el abandono de actividades como la agricultura o la pesca.

La fundación de Ciudad Pemex en 1958 correspondía con la expansión de una lógica extractiva impulsada desde el Estado y con la instrumentalización de arreglos corporativos. Ciudad Pemex albergó desde entonces a la mano de obra (tanto obreros como técnicos) originaria de otros estados, principalmente de Veracruz, encargada de la operación de la planta procesadora de gas.

El modelo contractual de la empresa pública de energía incorporó un conjunto de derechos colectivos como la seguridad en el empleo, la jubilación a los 30 años de servicio y el acceso a un conjunto de prestaciones como el crédito o el préstamo habitacional (Quintal, 1986). El mantenimiento de la infraestructura urbana y los costos de servicios básicos, como recolección de basura y distribución de agua, corrían a cargo de la empresa como una prestación a los trabajadores que habitaban en la ciudad. Estos vivieron en una ciudad planificada y con acceso a servicios urbanos a cargo de la empresa; tales como la distribución de gas subterráneo, agua potable y electricidad.

La economía de enclave encontró en el modelo de regulación monopólica estatal, en la configuración de la empresa pública nacionalizada y en la protección del empleo del trabajador petrolero, los soportes institucionales para la construcción de acuerdos corporativos y de un estatus protegido. Los arreglos que regulaban el acceso a la empresa posibilitaron la trayectoria del trabajador petrolero, hombre, principalmente en las áreas o 
departamentos operativos, haciendo que la historia de las familias petroleras estuviera estrechamente vinculada con la historia de la empresa. La posibilidad de intervenir en la asignación de una plaza o en la sustitución de una vacante, con la mediación de la representación sindical, se fue instituyendo como un "derecho" del trabajador petrolero bajo la premisa de asegurar la continuidad del trabajo y la estabilidad de la familia, referente importante en la definición de la identidad del trabajador petrolero.

A la luz de los cambios vividos en la última década, la época de esplendor de Ciudad Pemex es recordada con nostalgia por personas entrevistadas durante el trabajo de campo. Esta contrasta con la descripción que se hace hoy en día de la vida en la localidad: agotamiento de los yacimientos petroleros, reestructuración de la empresa y apertura del sector petrolero a la participación privada, que son identificados como factores que hacen la vida más incierta y precaria para el trabajador petrolero. Además, se constituyeron en condiciones propicias para la reforma de la empresa en 1992 (Rosendo, 2018) y la reorganización productiva del sector petrolero, así como para la ruptura de arreglos alrededor de la gestión del espacio público.

La recomposición de la empresa, la flexibilización del mercado de trabajo y los ajustes al marco de negociación contractual (regulación del empleo) son procesos que convergen en la desestructuración de los referentes — trabajo estable y sentimiento de incertidumbre - que expresan los trabajadores petroleros, ya que impactan en las lógicas de reproducción de la “familia petrolera" y en los planes a futuro de los jóvenes. El declive de la protección social se combina con la reforma al marco contractual de los trabajadores del sector y la redefinición de los arreglos políticos que inciden en la regulación del territorio. En este proceso, las disputas que se crean en el mercado de trabajo, por ocupar un puesto en la empresa, se acentúan con la reconversión productiva del sector y la extensión de la lógica de servicios, como la subcontratación, situación que crea mayores tensiones en el espacio social, debido a la "competencia" entre trabajadores por alcanzar un contrato estable o temporal. En este sentido, la apertura del sector energético y la conversión de la empresa se expresan en procesos de descalificación laboral y en la reducción de costos laborales. 


\section{Cambios en los trabajos de hombres y mujeres en Necaxa y Ciudad Pemex: pérdidas, ganancias, permanencias}

La robustez y estabilidad económica lograda por la "familia" petrolera y electricista, como decíamos, se basó en los acuerdos corporativos establecidos entre los sindicatos y la empresa que funcionaron durante décadas (Quintal, 1986; Belmont, 2016). Sin embargo, la reorganización productiva en el caso de Petróleos Mexicanos o propiamente el cierre de la empresa Luz y Fuerza del Centro sacudieron de manera brusca esos arreglos. Consideramos que, aunque algunas de las repercusiones se percibieron de inmediato, todavía está por verse el alcance que tendrán en las ciudades, caso de estudio, en el mediano y largo plazo.

Con base en información cuantitativa y cualitativa obtenida directamente en campo, en este apartado buscamos mostrar los “ajustes individuales" (González de la Rocha, 2000) que tanto los trabajadores directos de dichas empresas como sus familias tuvieron que hacer para mantenerse a flote. La pérdida del empleo del proveedor principal demandó la reorganización de la forma en que el núcleo familiar llevaba a cabo su reproducción social. Si bien las respuestas de los afectados por el cambio estructural se han dado dentro de los límites en los que han podido actuar, no todo ha sido pérdida (Cowie y Heathcott, 2003). En este apartado damos primero una imagen somera de la participación de hombres y mujeres frente al mercado de trabajo y posteriormente sus ajustes ante el embate de la desestructuración.

Los trabajos de hombres y mujeres en Necaxa y Ciudad Pemex

A continuación, presentamos algunos de los resultados de la encuesta diseñada ad hoc. Nos concentramos en la participación de hombres y mujeres entre la población económicamente activa (ocupados y desocupados) y la económicamente inactiva. 


\begin{tabular}{|cccc|}
\hline Cuadro 1. Situación de ocupación por sexo, Necaxa y Ciudad Pemex, 2016 \\
\hline \hline NECAXA & Total & Hombres (\%) & Mujeres (\%) \\
\hline Población ocupada & 209 & 68.4 & 31.6 \\
Población desempleada & 26 & 77.0 & 33.0 \\
Población económicamente inactiva & 417 & 34.1 & 65.9 \\
& & & \\
CIUDAD PEMEX & Total & Hombres (\%) & Mujeres (\%) \\
\hline Población ocupada & 235 & 72.8 & 27.2 \\
Población desempleada & 26 & 92.3 & 7.7 \\
Población económicamente inactiva & 433 & 29.3 & 70.7 \\
\hline
\end{tabular}

Fuente: Elaboración propia con base en la "Encuesta regional sobre impacto social de las reestructuraciones industriales".

En este cuadro 1 se observa que la fuerza de trabajo en ambos contextos de desestructuración del enclave energético sigue siendo preponderantemente masculina. Del total de ocupados en Necaxa, dos terceras partes son hombres y una tercera parte corresponde a las mujeres; en Ciudad Pemex la diferencia es mayor, pues tres de cada cuatro trabajadores son hombres y solamente una es mujer. La población desocupada, un número mínimo en estas cifras —hay que recordar que en el país la tasa de desocupación ha sido históricamente baja- es también mayoritariamente masculina.

En correspondencia con lo anterior, la "población económicamente inactiva" (gráficas 1 y 2), destaca la mayor presencia de mujeres en ambas ciudades. 


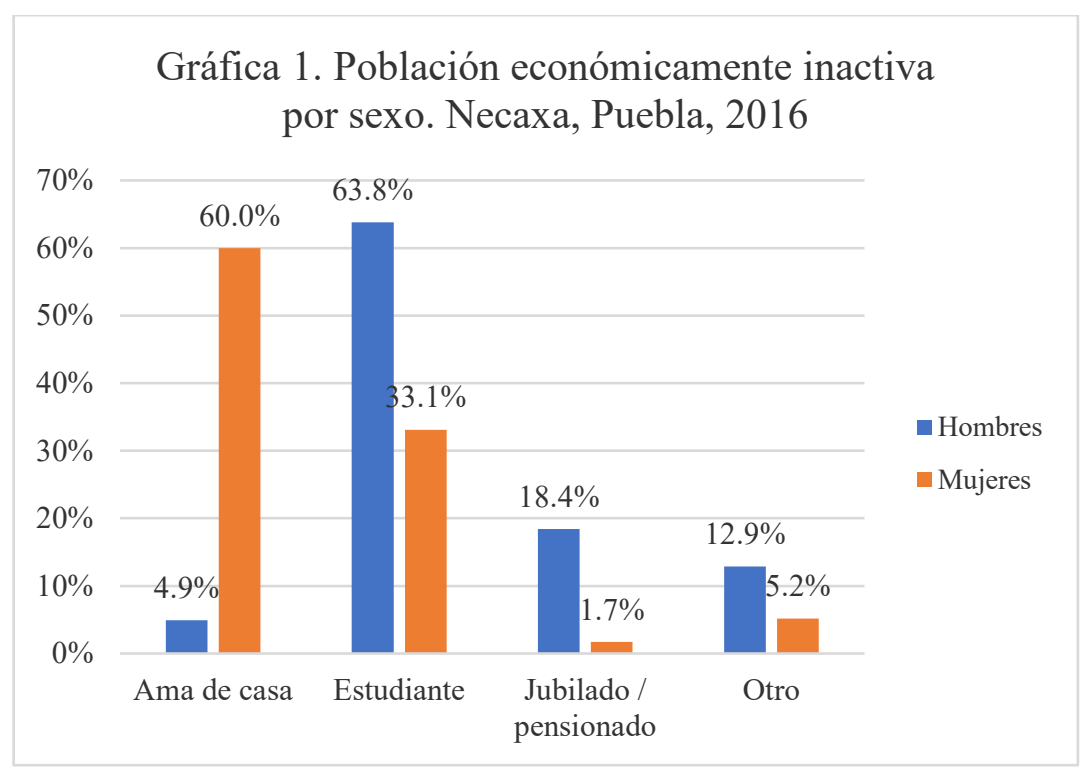

Fuente: elaboración propia con base en la "Encuesta regional sobre impacto social de las reestructuraciones industriales".

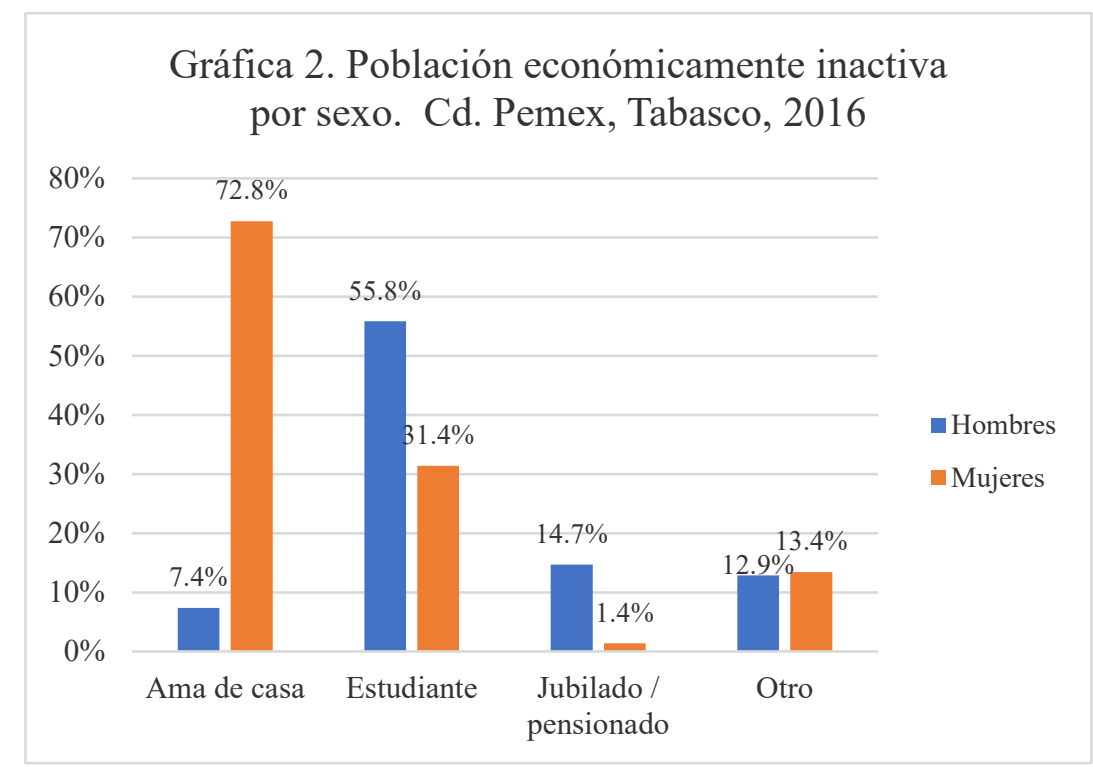

Fuente: elaboración propia con base en la "Encuesta regional sobre impacto social de las reestructuraciones industriales".

La categoría en la que más claramente se nota tal preponderancia es en la de "ama de casa". En Necaxa, del total de mujeres en la muestra, 60\% se dedica a tal actividad y en Ciudad Pemex son el 72.8\%. Aproximadamente una tercera parte de las mujeres se reporta como estudiante y una mínima proporción son jubiladas o pensionadas. En cambio, si se observa 
la distribución de los hombres en las diferentes categorías de inactivos, destaca la escasa participación masculina en las labores del hogar — como se ha documentado ampliamentepero comparativamente acusan una proporción considerablemente más alta que las mujeres entre los estudiantes y entre los jubilados, tanto en Necaxa como en Ciudad Pemex.

En particular, la categoría de los jubilados merece especial atención. En Necaxa la participación de los hombres es de 18. 4\% frente a 1.7\% de las mujeres. En Ciudad Pemex $14.7 \%$ frente a $1.4 \%$ de las mujeres. Esta desigualdad se explica, consideramos, por la vigencia del modelo breadwinner cuando dichas personas eran fuerza de trabajo activa.

\begin{tabular}{|c|c|c|c|}
\hline \multirow{2}{*}{\multicolumn{4}{|c|}{$\begin{array}{c}\text { Cuadro 2. Trabajadores asalariados según calificación y seguridad social } \\
\text { por género } \\
\text { Con seguridad social }\end{array}$}} \\
\hline & & & \\
\hline NECAXA & Total & $(\%)$ & Sin seguridad social \\
\hline Hombres - Calificados & 63 & 54.0 & 46.0 \\
\hline Hombres - No calificados & 68 & 20.6 & 79.4 \\
\hline Mujeres - Calificadas & 54 & 48.1 & 51.9 \\
\hline \multirow[t]{2}{*}{ Mujeres - No calificadas } & 78 & 24.4 & 75.6 \\
\hline & 263 & & \\
\hline \multirow[b]{2}{*}{ CIUDAD PEMEX } & \multicolumn{2}{|c|}{ Con seguridad social } & \\
\hline & Total & $(\%)$ & Sin seguridad social \\
\hline Hombres - Calificados & 49 & 46.9 & 53.1 \\
\hline Hombres - No calificados & 37 & 27.0 & 73.0 \\
\hline Mujeres - Calificadas & 43 & 34.9 & 65.1 \\
\hline \multirow[t]{2}{*}{ Mujeres - No calificadas } & 50 & 26.0 & 74.0 \\
\hline & 179 & & \\
\hline
\end{tabular}

Fuente: Elaboración propia con base en la "Encuesta regional sobre impacto social de las reestructuraciones industriales".

En el cuadro 2 se observa que la calificación de la fuerza de trabajo asalariada no implica su acceso a la seguridad social en estas localidades, otrora dinámicos enclaves energéticos. En Necaxa la proporción de hombres calificados con seguridad social es de $54 \%$, en tanto que en Ciudad Pemex es menor (46.9\%); en consecuencia, también entre los hombres, la cifra de 
quienes, a pesar de su calificación, no tienen seguridad social, en Necaxa asciende a 46\%, en tanto que en Ciudad Pemex esa cifra es de 53.1\%. Por otra parte, la falta de calificación representa una considerable desventaja para obtener seguridad social: 20.6\% en Necaxa y 27\% en Ciudad Pemex. Comparativamente, sin embargo, las mujeres calificadas están en mayor desventaja que los hombres, pues en Necaxa solamente el 48.1\% tienen acceso a la seguridad social y en Ciudad Pemex el 34.9\%; las mujeres no calificadas, igual que su contraparte masculina, en muy baja proporción acceden a la seguridad social: $24.4 \%$ en Necaxa y $26 \%$ en Ciudad Pemex.

\section{Un shock para la familia petrolera y electricista}

Las narrativas sobre la familia petrolera señalan la historia de la planta y de la creación de Ciudad Pemex, fundada en 1958. Es decir, la fundación del enclave petrolero bajo el discurso del nacionalismo revolucionario y de la valoración de saberes técnicos, vistos como recursos, en el dominio sobre la naturaleza. En las entrevistas que se desarrollaron en el periodo de trabajo de campo, la palabra era acaparada por la figura masculina, quien daba cuenta de la trayectoria de la familia, claramente orientada por la caracterización de un linaje masculino y petrolero:

Soy la cuarta generación de petroleros, desde mi bisabuelo que trabajó en la compañía petrolera de El Águila. Con la expropiación petrolera, mi abuelo trabajó donde se expropió [el petróleo], él trabajaba en el pozo cuatro, en Veracruz. Entra mi abuelo ya como Pemex, era Petróleos Mexicanos, entró a trabajar en Poza Rica (Veracruz). Después entró mi padre, él ya es jubilado; entró en el departamento de petroquímica; estuvo en Reynosa, en Tuxpan, en Poza Rica. Nosotros somos personas de las que se dispone si se requiere, somos el material de recursos humanos, la empresa tiene la facultad de movernos de un lugar a otro; yo he estado en Baja California, en Yucatán, en Poza Rica, en Salamanca, aquí en Ciudad Pemex (Roberto ${ }^{4}$, Ciudad Pemex).

\footnotetext{
${ }^{4}$ Con el propósito de preservar la identidad de los informantes, emplearemos pseudónimos en estas citas.
} 
El orgullo de pertenecer a la familia petrolera se reproducía también de generación en generación. Estaba respaldado por el discurso de la importancia económica de la empresa a la que prestaban sus servicios, además de que palpaban las buenas condiciones que les permitía ofrecer a sus familias de procreación. Los trabajadores eran recursos disponibles para la empresa que los movía de lugar según fuera necesario — y las esposas seguían la directriz de sus maridos - pero les correspondía con ingresos remuneradores y, en general, buenas condiciones de trabajo. En Ciudad Pemex:

Fue a la par, estaban haciendo las casas y la planta, entonces tenían que movilizar a la gente, primero vinieron los contratistas, empezaron a hacer los pozos y venían en campamentos. Aquí eran puros pantanos, entonces cuando vinieron, ya iban a movilizar a las 320 familias de varios lugares de Pemex. Los movilizados venían de Minatitlán, a ellos les asignaron las casas que fueron pagadas por Pemex, descontadas al trabajador por 20 años; son terrenos de 600 metros cuadrados, 30 x 20, son 600 metros cuadrados. Yo me fui de aquí, saliendo de la escuela me fui a Reforma, Chiapas a las primeras plantas. Yo no tenía todavía planta en Pemex, mi papá si era de planta. Me podía haber quedado aquí, pero me fui porque me gustó siempre salir. Como mi papá se jubiló, todas mis hermanas grandes ya tenían planta, a mí me la dio mi papá; yo vine a firmar la planta con Gonzalo, quien fue Secretario General, en ese entonces... (Javier, Ciudad Pemex).

La creación de la planta procesadora de gas se desarrolló, sobre todo, con la participación de fuerza de trabajo masculina (migrante) con experiencia en el sector petrolero. El modelo de familia nuclear con el varón proveedor dio la directriz al ofrecer las unidades habitacionales y los servicios urbanos a los trabajadores de la empresa.

Mi esposo es petrolero, por eso nos movimos; de hecho, no soy originaria de Ciudad Pemex, la mayoría de aquí no somos originarios, pero ya tengo 23 años viviendo por acá. Entonces, así como todos los que hemos llegado, venimos de lugares cercanos como Veracruz, Oaxaca, Chiapas, yo soy de 
Minatitlán. Precisamente por las situaciones de trabajo de mi esposo es que vengo a dar a Ciudad Pemex. Nosotros venimos acá por la propuesta que le hacen a mi esposo, y él dijo: "pues vámonos a donde sea", y así es como nos instalamos en Ciudad Pemex (Claudia, 2016).

La apertura del sector energético al capital privado, la reorganización productiva y la flexibilización del mercado de trabajo convergieron en la redefinición del papel de las mujeres en el sector petrolero. Si bien el desarrollo de tareas administrativas y de servicios ha registrado participación de fuerza femenina, las áreas operativas se han mantenido en buena medida como espacios masculinizados.

La reestructuración de la empresa estatal justificó, por otra parte, la redefinición de arreglos corporativos en la búsqueda de la flexibilización del mercado de trabajo. La pérdida de control sindical sobre el ingreso a la empresa (la posibilidad de heredar plazas) se combinó con la apertura del sector energético y, por lo tanto, con la licitación de zonas de explotación de hidrocarburos. Esto creó un espacio de incertidumbre sobre la estabilidad laboral y la reproducción del modelo de la familia petrolera. Si bien la representación del hombre proveedor prevalece como una tipología social hegemónica, la reestructuración de la empresa ha impactado en el modelo de reproducción de la familia petrolera. La incertidumbre que se genera en el ámbito doméstico se ubica en la ruptura de acuerdos que permitan la continuidad del modelo breadwinner.

Por otra parte, el anuncio del cierre de LyFC llegó a Necaxa en una noche de octubre de 2009 de manera abrupta e inesperada. Todavía no terminaba ese año cuando el Sindicato Mexicano de Electricistas anunció que daría la batalla con un movimiento de resistencia, a fin de recuperar la fuente de trabajo para los 16 mil trabajadores que no aceptaron el finiquito ofrecido por el gobierno federal. Esos años se vivieron bajo una fuerte tensión que llegó hasta el ámbito doméstico, no solamente por la falta de los ingresos regulares y la incertidumbre ante el futuro, sino también porque entre las diferentes generaciones de electricistas en una familia hubo, por ejemplo, hermanos electricistas que optaron por el finiquito o por la resistencia, lo que los convirtió en antagonistas (Belmont, 2013; Victoria, 2013). 
La pérdida del empleo generó procesos de negociación en el espacio doméstico. El papel asignado a las esposas de los trabajadores se puso en tensión con la pérdida del ingreso. Para empezar, inesperadamente se volvieron partícipes de los acuerdos en la familia nuclear respecto de la conveniencia de que el marido aceptara la liquidación, ofrecida con el cierre de la fuente de trabajo, u optar por la resistencia. No obstante, la figura de la resistencia permitió enfrentar las faenas de la vida cotidiana como la pérdida del papel de jefe proveedor en un contexto social y económico muy adverso para la inserción en el mercado laboral (Belmont, 2013; Victoria, 2013).

La decisión de mantenerse en la resistencia demandó el diseño de estrategias para generar un ingreso para la manutención del hogar. En este sentido, un amplio sector de mujeres decidió salir de su casa en la búsqueda de un soporte económico para mantener la participación de los hombres en la resistencia, en parte, con la expectativa de que la reinserción de su esposo al trabajo permitiría el retorno de ella al espacio doméstico y a las actividades de cuidado. Así:

Yo creo que hubo mucha gente que se acostumbró. Para nosotros fue un año de trabajo; por ejemplo, hay mucha gente mayor que yo, que no estaba acostumbrada a hacer otro tipo de cosas, que solamente percibían un gasto, un salario, como sea, pues muchas [mujeres] sí se quedaron así, como decir “y ahora, ¿qué hago?” Pero muchos sí recurrieron al negocio, aquí se llenó de negocio; yo creo que todos nos comprábamos a todos, es un pueblo que, creo, se ha mantenido de eso (Rosa, Necaxa).

Entre los testimonios recabados en campo destaca la inestabilidad que el cierre de LyFC trajo a las familias de electricistas. Así, el desacuerdo — por ejemplo, la presión de las esposas para que sus esposos aceptaran el finiquito — o la demanda de ellas de un nivel de vida similar al que tenían antes del cierre, cuando ellos ya no percibían ingresos, llevó a rupturas matrimoniales o enfermedades que derivaron en muertes. 
No obstante, es de destacar el inesperado papel de los jubilados. Por una parte, se ha reconocido a la figura del jubilado por su apoyo moral y económico — con su presencia y apoyo directo - al movimiento de la resistencia, además de que fueron identificados como actores clave en el sostén de la familia ampliada, pues hicieron una aportación regular a sus hijos electricistas que no aceptaron el finiquito y a sus familias. Por otra parte, los jubilados, sin proponérselo, se convirtieron en agentes con poder económico. Hombres la gran mayoría de ellos, recobraron el lugar que habían tenido cuando eran los proveedores principales de sus propias familias, pues eran los únicos con ingresos regulares. Con ello, la figura del jubilado reprodujo el esquema patriarcal toda vez que, por ejemplo, sus nueras, las esposas de sus hijos en resistencia, dependían de los ingresos - de la cantidad que él decidiera aportar - para acceder a bienes básicos para la reproducción de la familia.

Entre los testimonios obtenidos en campo, un sector de las esposas de los trabajadores en resistencia manifestó gratitud a la figura del jubilado por el apoyo económico. El sentimiento de dependencia, sin embargo, llevó a que algunas de las nueras realizaran trabajo doméstico sin pago, en reciprocidad por esa "ayuda" económica, lo que reprodujo la naturalización de las actividades domésticas entre las mujeres dependientes. Desde la perspectiva del jubilado, el pago a las nueras por actividades domésticas se realizaba con la premisa de asegurar que la "ayuda" económica permaneciera con la familia en resistencia. Uno de los testimonios sobre lo crítico de la situación y el apoyo que recibieron es el siguiente:

Toda la familia de mi esposo es de electricistas. Nosotros conformamos una familia de seis, somos mi esposo, mis cuatro niñas y yo. Todas las niñas son menores de edad. Estábamos viviendo en [la ciudad de] México, cuando surgió el golpe del decreto. Posteriormente, nos regresamos a Necaxa todos. Somos originarios de aquí [...] nos venimos porque allá nos sentimos muy solos, abandonados. Entonces, ya llegamos aquí, mi esposo no encontraba trabajo, él tiene 51 años, [es] mucho mayor que yo. Buscó, le dieron un trabajo muy mal pagado, [...]llegó al grado en que yo les dijera a mis niñas: "hijas va a haber días en que no haya de comer, el día que les diga ya no hay de comer, no me pidan", o sea, así, fue muy fuerte, fue muy cruel. Y pasó, era un día, a 
las 12 de la noche, mis hijas no tenían que comer, [...] andábamos, como vulgarmente se dice, de arrimados. Fue muy fuerte. [...] mis niñas pedían para la escuela, seguían estudiando, gracias a Dios no dejaron de estudiar con el apoyo de mi suegro, de mis papás y de un tío de mi esposo, que en paz descanse (Elena, Necaxa).

Otra situación del reforzamiento del sistema patriarcal lo notamos en el alarde que los jubilados hacían sobre el poder de atracción que, súbitamente, tenían sobre las mujeres jóvenes de la comunidad, derivado, según ellos, de su poder económico posterior al cierre de LyFC: “Ahora, resulta que los jubilados somos los más chulos de Necaxa” era una expresión común entre ellos. Más allá del alarde, en campo documentamos casos de emparejamientos de mujeres jóvenes con jubilados, que tuvieron lugar en el periodo de la resistencia.

\section{Identidades cambiantes}

Durante décadas, los trabajadores que encabezaron a las familias petroleras y electricistas tuvieron una fuerte integración social. Pero la inestabilidad laboral vino a cuestionar los pilares de jefe proveedor y de orgullo laboral y profesional.

La reestructuración del sector petrolero ha significado cambios en el régimen de contratación y en la regulación del mercado de trabajo. La apertura del mercado de hidrocarburos, el modelo de trabajar por proyecto y la instrumentalización de herramientas gerenciales apuntalaron la flexibilización del mercado de trabajo. Para el trabajador sindicalizado, los ajustes en los acuerdos contractuales, en particular en las cláusulas relativas a la jubilación, se combinaron con lo que se percibió como un ataque a los pactos que permitían, por ejemplo, la posibilidad de heredar las plazas, lo que se consideraba una prerrogativa entre ellos. Los trabajadores sindicalizados han resentido este proceso con la clausura de ciertos derechos, considerados hasta entonces como un patrimonio del colectivo de trabajadores.

Parece que la posibilidad de que haya continuidad de la familia en la empresa se ha agotado, ya no quieren respetar el derecho de dejar a alguien, de hecho 
los que se están jubilando ahorita, a partir del primero de junio, una jubilación masiva, no les quieren dejar el transitorio por su jubilación, no quieren dejar hacer uso de ese derecho, derecho de antigüedad, por ejemplo, si nos jubilamos nosotros cinco y él ya dejó (a un familiar) y nosotros no hemos dejado, entonces se va a dejar al hijo o hermano de nosotros que tenga mayor antigüedad. Entonces es una plaza para cuatro, y hay que esperar a que vuelva a salir otra jubilación. Tenemos las últimas plazas congeladas, según todo viene de México (Esteban, 2016).

Los cambios en el régimen de jubilación (2015) fueron interpretados como parte de la redefinición de los arreglos contractuales y de los ajustes anunciados en la conversión de Pemex en empresa productiva del Estado. Dichos cambios se apoyaron en buena medida en la descalificación del trabajador petrolero al ser presentado como un actor privilegiado y protegido por el régimen corporativo.

Consideramos que, dado que en Necaxa se dio una ruptura abrupta de los arreglos corporativos previos, sus repercusiones han cimbrado lo que era un sistema de reproducción relativamente estable. Es en Necaxa donde observamos que las identidades se han trastocado más: entre los varones que ven cuestionado su papel de proveedor seguro de su familia y su identidad electricista; entre las mujeres, su participación en el movimiento de resistencia redundó en cierta politización y su inserción en actividades económicas les permitió tener perspectivas más amplias sobre su potencial.

La situación vivida con el despido y con el desempleo puso a prueba los marcos que encuadran la distribución de roles en la familia. La dificultad de reinsertarse a un empleo estable, frente a las condiciones que imperaban en el mercado de trabajo, se expresa en una ruptura con los referentes políticos e identitarios de los trabajadores despedidos. La búsqueda de un "verdadero" trabajo significaba entonces no sólo la obtención de la protección mediante un contrato formal y la afiliación a un colectivo; sino también, la certeza de garantías en términos de retribución para cumplir con las responsabilidades socialmente asignadas al sexo masculino. Si bien la pérdida del empleo y de la fuente de ingresos estables trastocó las 
rutinas de hombres y de mujeres, la experiencia vivida por los hombres es interpretada como un quiebre o como una ruptura que los colocó en un impasse debido, entre otros, a la dificultad de aceptar las condiciones impuestas por la flexibilización del mercado de trabajo. Destaca, al respecto, el siguiente testimonio, en el que se reflexiona sobre la fragilidad masculina frente al quiebre de estos marcos referenciales:

Todos estamos en una posición muy sensible y sí nos afecta, a cualquier hombre, yo creo. Las mujeres lo han vivido un poco diferente y no quiero hacerlas menos, pero cuando nos quitan la seguridad económica, nos quitan todo. A algunos les quita hasta la hombría, a otros les quita el futuro, la seguridad; entonces, mantenernos inseguros, todo el tiempo, es un detonante de muchas cosas. Afortunadamente somos muchos los que hemos reaccionado positivamente, el detonante nos ha hecho sacar fuerzas, nos ha hecho ser más creativos, más propositivos en muchos aspectos y también ahorrar energías (Juan, Necaxa).

En ese sentido, la defensa del trabajo, a través del movimiento de resistencia, tiene de trasfondo el anhelo de recuperar la identidad debilitada de jefe proveedor y otros referentes, como la seguridad en sí mismo que le otorgaba su trabajo. Según otro electricista en resistencia: "Orgulloso por haber hecho el llamado a la resistencia. Estar en la resistencia es amar la camiseta porque pues antes había un salario digno de por medio que te permitía que tus hijos estudiaran, que tu mujer no trabajara, ahora no. Estar en la resistencia es retribuir todo lo que se nos quitó" (Artemio, Necaxa).

El movimiento de resistencia tuvo una arista novedosa: un proceso de politización de las mujeres. Además de la defensa del trabajo que se expresó en el apoyo al padre, al marido o al hijo, existen diversos testimonios sobre la revelación de una dimensión política que para muchas fue su salida del ámbito doméstico para tomar las calles y plazas. Los siguientes testimonios dan cuenta de esta lógica: 
Aquí era un pueblo productivo, era un pueblo con dinero. Yo soy ama de casa y viuda, mi hijo está desempleado; tenía 10 años de servicio en la empresa (LyFC), es ingeniero eléctrico y no hay trabajo para ellos, en ninguna parte. En apoyo a él, a mi papá — mi papá es jubilado—, a mis hermanos, que también son jubilados, todos somos de Luz y Fuerza, participo en la resistencia, en las marchas y los mítines (Martha, Necaxa).

En la localidad escuchamos diversos testimonios en los que se reconoce el papel de las mujeres como un apoyo importante para el desarrollo de la resistencia. Este despertar político, sin embargo, se dio dentro del marco de la división sexual del trabajo previamente conocida. En el movimiento de resistencia, más que dirigentes, fueron acompañantes; no obstante, su participación implicó un aprendizaje importante, pues se reconocieron entre sí y frente a quienes no participaban o no compartían sus inquietudes. En ese despertar también se dieron cuenta de que la falta de un empleo estable y el ingreso seguro, de parte de quienes habían sido los proveedores principales en su hogar, para ellas implicaba que su participación económica resultaba necesaria. Al respecto, la señora Matilde que salió a apoyar a su esposo en la resistencia, dijo enfática: "Me aguanté la vergüenza y salí a vender lo que fuera, recorrí Tenango [localidad aledaña a Necaxa], dejaba a mis hijos, lo que nunca hacía antes, pero vi

que sí podía llevar dinero a mi casa. Conocí a otras señoras como yo en la resistencia... [le digo a mi marido] ya que salí a la calle, ya no pienso encerrarme en mi casa.”

\section{Comentario final}

En este artículo nos planteamos examinar las repercusiones de la desestructuración del sector energético, sobre la participación de hombres y mujeres en las esferas laboral y doméstica; asimismo nos preguntábamos, en esos cambios, qué reciben o dejan de recibir en términos de poder, prestigio y autoestima. Señalábamos que un reto de esta investigación ha sido documentar un fenómeno que está en proceso, toda vez que los ajustes en la vida cotidiana de las familias y las localidades afectadas están en marcha todavía. 
Mostramos que, a partir de arreglos corporativos que por décadas existieron entre los trabajadores y la empresa — mediante el apoyo y negociación del sindicato - se mantuvo una lógica de reproducción basada en dos pilares. Por una parte, la defensa de un modelo de "familia" (petrolera o electricista) que se reprodujo mediante el cuidado del patrimonio básico que era la fuente de trabajo. Estaba consignado en el contrato colectivo de trabajo que, al jubilarse, el trabajador transmitía su plaza a un pariente directo. En Ciudad Pemex esa prerrogativa se ha perdido y los ajustes por la desestructuración del enclave se perciben más de manera individual. En Necaxa la posibilidad de mantener esta familia se perdió de forma tajante cuando su fuente de trabajo fue declarada extinta por un decreto presidencial en octubre de 2009.

Por otra parte, con la pérdida del empleo quedó negada la posibilidad de mantener el canon de familia de procreación con base en el modelo breadwinner. La pérdida de coherencia en el contrato de la familia nuclear proletaria se expresa en un conjunto de tensiones a las que las mujeres (en tanto amas de casa) se enfrenta, no sólo, por ejemplo, con la pérdida de regularidad en el ingreso, que representa el gasto corriente familiar; sino también, con la necesidad de desarrollar estrategias que les permitan conciliar la vida doméstica y laboral.

La pérdida del empleo y el incremento de la inseguridad laboral abrieron algunas interrogantes sobre los papeles asignados a la mujer y al hombre. Ambos han tratado de reproducir los roles tradicionales de género porque en esos valores han sido socializadas generaciones de trabajadores del sector energético. De esta manera, los hombres tratan de mantener su papel de proveedor principal, que se ve crudamente cuestionado al haber perdido la fuente de ingreso y de seguridad para su familia. Como lo dijo alguno de nuestros informantes, "si te quitan el trabajo, te quitan todo...hasta la hombría". Ese trastocamiento del papel de proveedor principal se acentuó cuando quien cubría esa función se vio parcialmente sustituido por el apoyo de un agente (el jubilado) que previamente a este ajuste macroestructural no se encargaba de la manutención de sus hijos y sus familias, pues para ello contaban con un empleo con seguridad social y de por vida. 
En correspondencia, las mujeres que no participaban en la fuerza de trabajo se ven forzadas a salir en la búsqueda de un ingreso. La expectativa de ellas al salir a apoyar el movimiento de resistencia era que al recuperar el esposo (hermano, hijo) su fuente de trabajo, volverían a los arreglos domésticos que tenían antes. El movimiento de resistencia en Necaxa trajo la novedad de una ventana a la politización de las mujeres al salir a las calles y no todas están dispuestas a volver a "encerrarse" en su casa, como lo manifestaron en campo. De alguna manera, a partir de la desestructuración del sector energético se ha cuestionado la tradicional división sexual del trabajo.

\section{Agradecimientos}

El artículo forma parte de los compromisos con el Consejo Nacional de Ciencia y Tecnología (CONACYT) en el marco del proyecto "Desestructuración de enclaves energéticos" en el que participamos los autores. Nuestro agradecimiento a los alumnos de licenciatura en antropología de la Universidad Autónoma de Querétaro que participaron en el trabajo de campo para sus trabajos de tesis. Agradecemos en particular las observaciones que recibimos en dos dictámenes anónimos porque nos ayudaron a mejorar una versión previa de este texto.

\section{Referencias bibliográficas}

Belmont, Edgar. (2013). Despido y sentimientos de injusticia. El caso de los trabajadores electricistas. En Eleocadio Martínez y Mario Jurado (Coords.), Crisis, Calidad de Empleo y Desempleo (pp. 99-125). México: Universidad Autónoma de Nuevo León.

Belmont, Edgar. (2016). La desestructuración del mundo de los electricistas. El cierre de Luz y Fuerza del Centro y los horizontes de vida como campo de disputa. México: Universidad Autónoma de Querétaro.

Bortz, Jeffrey y Águila, Marcos. (2006). Earning a Living. A History of Real Wage Studies in Twentieth Century Mexico. Latin American Research Review, 41(2), 112-138. Recuperado de http://www.helsinki.fi/iehc2006/papers2/Bortz_Aguila.pdf

Brenner, Johanna. y Ramos, María. (1984). Rethinking Women's Oppression. New Left Review, (144), $42 \quad-44 . \quad$ Recuperado de 
https://pdfs.semanticscholar.org/9201/22f5ffd7db549d04583e8010bc969e7264c2.pdf ? ga=2.57607981.60664088.1591815880-908759109.1591815880

Colín Macías, Tania Gabriela. (2018). Las tres Necaxa en disputa; identidad, memoria y resistencias (Tesis de Licenciatura en Antropología Social). México: Universidad Autónoma de Querétaro.

Contreras, Camilo. (2002). Espacio y Sociedad. Reestructuración espacial en un antiguo enclave minero. México: El Colegio de la Frontera Norte, Plaza y Valdés.

Cowie, Jefferson y Heathcott, Joseph. (2003). Introduction. The Meanings of Deindustrialization. En Jefferson Cowie y Joseph Heathcott (Eds.), Beyond the ruins. The Meanings of Deindustrialization (pp. 1-15). New York: ILR Press.

De Barbieri, Teresita. (1984). Mujeres y vida cotidiana. México: SEP, FCE.

De la Garza, Enrique. (1998). Modelos de industrialización en México. México: Universidad Autónoma Metropolitana.

De la Garza, Enrique, Lara Flores, Sara Ma. y Torres Franco, José Luis. (2001). Flexibilidad y empleo femenino en la industria manufacturera de México. Revista Mexicana de Sociología, 63(2), $113-136$.

De la O. Martínez, María Eugenia. (2000). Flexibilidad, trabajo y mujeres: ausencia y presencia en los estudios de trabajo en México (1988 - 1998). Región y Sociedad, XII (19), $83-134$.

Dussel Peters, Enrique. (1995). El cambio estructural del sector manufacturero mexicano, 1988-1994. Comercio Exterior, 45(6), 460-469. Recuperado de https://dusselpeters.com/171.pdf

Estrada, Margarita. (1996). Después del despido. Desocupación y familia obrera. México: CIESAS. 
Federici, Silvia. (2018). El patriarcado del salario. Críticas feministas al marxismo. Madrid: $\begin{array}{llll}\text { Traficantes de } & \text { sueños. }\end{array}$ https://www.traficantes.net/sites/default/files/pdfs/TDS_map49_federici_web_0.pdf

González de la Rocha, Mercedes. (2000). Private Adjustments: Household Responses to the Erosion of Work. New York: UNDP.

Gutiérrez Gil, Roberto. (1950). Yacimientos Petrolíferos en la Región de Macuspana, Tabasco, Boletín AMGP, 2(8). 499-510. Recuperado de http://archives.datapages.com/data/amgp/pdfcontent/1950/1950_Ago_Yacimientos_Petroliferos_Region_Macuspana_TabascoX2. $\underline{\mathrm{htm}}$

Hirata, Helena. (1998). Restruturação produtiva, trabalho e relações de gênero. Revista Latinoamericana de Estudios del Trabajo, 4(7), 5 -27.

Hirata, Helena y Kergoat, Danièle. (1993). La classe ouvrière a deux sexes. Politis. La Revue. (4), 55-58.

Lara Flores, Sara María. (1991). Las obreras agrícolas: sujeto social en movimiento. Nueva Antropología, $\quad X I(39), \quad 99 \quad-\quad 114 . \quad$ Recuperado de https://www.redalyc.org/pdf/159/15903907.pdf

Martínez Silva, Eleocadio. (2009). Convertirse en ex obreros. Cambios y continuidades en las identidades de los trabajadores de Fundidora de Monterrey. México: Universidad Autónoma de Nuevo León.

Olivo Pérez, Miguel Ángel. (2005 ). Trabajo y familia: posiciones optimistas y pesimistas en torno a la inestabilidad laboral. Estudios Sociológicos, 23(69), 879 - 892. Recuperado de https://www.redalyc.org/articulo.oa?id=59806907

Pacheco, Edith y Blanco, Mercedes. (2011). Tiempos Históricos, contextos sociopolíticos y la vinculación familia- trabajo en México: 1950-2010. En Julia Flores. (Coord.), A 50 
años de la cultura civica: pensamiento y reflexiones en honor al profesor Sidney Verba, (pp. 47 - 76). México: UNAM, Tribunal Electoral del Poder Judicial de la Federación.

Quintal, Ella Fanny. (1986). Sindicato, empresa y familia: los espacios de la reproducción de la fuerza de trabajo petrolera. Nueva Antropología, VIII(29), 107 - 122. Recuperado de https://www.redalyc.org/articulo.oa?id=15902707

Ravelo Blancas, Patricia. (2001). Clase y género, ¿Dos conceptos irreconciliables a finales de milenio?: notas para un debate. Nueva Antropología, XVIII(59), 145 - 160. Recuperado de https://www.redalyc.org/pdf/159/15905908.pdf

Reyes Soto, Itzel. (2018). Jóvenes frente a la reestructuración del trabajo, la construcción de nuevas representaciones laborales. El caso de Nuevo Necaxa, Puebla. En Edgar Belmont Cortés, Eleocadio Martínez Silva y Georgina Rojas García (Coords.), Emerger de los escombros. Nuevos contextos y nuevos actores de la reestructuración productiva en México (pp. 299 - 318). México: Universidad Autónoma de Querétaro, Universidad Autónoma de Nuevo León, Plaza y Valdés.

Roberts, Bryan. (1991). The Changing Nature of Informal Employment: The Case of Mexico. En Guy Standing and Victor Tokman (Eds.), Towards Social Adjustment. (pp. 115140). Ginebra: International Labour Office.

Rojas García, Georgina. (2007). Cuando yo me reajusté... Reestructuración económica local y ajustes individuales entre trabajadores manuales. Monclova, Coahuila, década de los noventa. En Margarita Estrada y Pascal Labazée (Coords.), Globalización y localidad: Espacios, actores, movilidades e identidades (pp. 483 - 502). México: CONACYT, IRD, CIESAS.

Rojas García, Georgina (2013). Transformación de la estructura económica en Monclova, Coahuila: La experiencia de enfrentar la heterogeneidad laboral en una ciudad industrial. En Eleocadio Martínez Silva y Mario Alberto Jurado Montelongo (Coords.), Crisis, calidad del empleo y desempleo (pp. 41 - 72). México: Universidad Autónoma de Nuevo León. 
Rosendo, Josué. (2018). La calificación del ingeniero petrolero como eje de disputa en el marco de transformación de Pemex y la formación profesional. En Edgar Belmont Cortés, Eleocadio Martínez Silva y Georgina Rojas García (Coords.), Emerger de los escombros: nuevos contextos y actores de la reconversión industrial (pp. 319 - 355). México: Universidad Autónoma de Querétaro, Universidad Autónoma de Nuevo León, Plaza y Valdés.

Seccombe, Wally. (1993). Weathering the Storm. Working-class Families from the Industrial Revolution to the Fertility Decline, Gran Bretaña: Verso.

Victoria, Gabriela. (2013). Reconstrucción de la identidad y acción colectiva del trabajador electricista de Necaxa. Ponencia, VII Congreso Latinoamericano de Estudios del Trabajo, Sao Paul, Brasil.

Zapata, Francisco. (1977). Enclaves y sistemas de relaciones industriales en América Latina. Revista Mexicana de Sociología, 39(2), 719 - 731.

Zepeda, Eduardo, Timothy A. Wise y Kevin P. Gallagher. (2009). Rethinking Trade Policy for Development: Lessons from Mexico under NAFTA, (Carnegie Endowment for International Peace Policy Outlook, Washington, D. C.). Recuperado de http://carnegieendowment.org/files/nafta_trade_development.pdf

\section{Sobre los autores}

Georgina Rojas García es doctora en sociología por la Universidad de Texas en Austin. Profesora-investigadora del Centro de Investigaciones y Estudios Superiores en Antropología Social (CIESAS), México. Es integrante del Sistema Nacional de Investigadores, Nivel 1. Las líneas de investigación que ha trabajado en años recientes son reestructuración económica y mercado de trabajo; migración internacional, empleo y familia; trabajo doméstico remunerado. 
Eleocadio Martínez Silva es doctor en sociología por El Colegio de México. Profesor investigador de la Facultad de Filosofía y Letras de la Universidad Autónoma de Nuevo León (UANL). Monterrey, México. Sus líneas de investigación son: identidades laborales y profesionales. Integrante del Sistema Nacional de Investigadores, Nivel 1.

Edgar Belmont Cortés es doctor en sociología por la Universidad de Evry (Francia) y en estudios sociales por la Universidad Autónoma Metropolitana. Profesor - investigador de la Facultad de Filosofía y Letras de la Universidad Autónoma de Querétaro (UAQ) en el área de antropología. Su campo de investigación se inscribe en el estudio del trabajo y la organización productiva, las organizaciones sindicales y el espacio social. Integrante del Sistema Nacional de Investigadores, Nivel 1. 